\title{
From Framingham to North Karelia to U.S. Community-Based Prevention Programs: Negotiating Research Agenda for Coronary Heart Disease in the Second Half of the 20th Century
}

\author{
Gerald M. Oppenheimer, PhD, MPH, \\ Henry Blackburn, MD, ${ }^{2}$ \\ Pekka Puska, MD, PhD, MPolSc ${ }^{3}$
}

\begin{abstract}
In the United States in 1948, the newly formed National Heart Institute (NHI) responded to what its data showed as a rising tide of coronary heart disease (CHD) by underwriting new approaches to the elucidation of chronic disorders. In the process, it funded the application of epidemiology, previously almost exclusively concerned with communicable disease, to study CHD. With federal encouragement, CHD epidemiologists enriched research designs, helped develop the randomized controlled trial, and played a pioneering role in chronic disease prevention at the individual and population levels. While government funding was critical to the evolution of this rich scientific work, a vibrant epidemiological imagination was able to capitalize on decades of national political commitment to chronic disease research. Epidemiologists developed longitudinal studies meant to determine the relationship between well-measured clinical variables and subsequent CHD events. Here, consistent associations within and across populations, eventually reinforced by analyses of pooled data from multiple cohort investigations, demonstrated the existence of well-founded risk factors, but left open the question of causal inference based on observed relationships. After substantial ambivalence, the U.S. government, under pressure from epidemiologists, committed to an agenda of clinical trials to test that proposition. In addition, the results of the cohort studies elicited a demand by epidemiologists for a broader, population-wide approach,
\end{abstract}

\footnotetext{
${ }^{1}$ Gerald M. Oppenheimer, Broeklundian Distinguished Professor, Brooklyn College and the Graduate Center, City University of New York and Center for the History and Ethics of Public Health, Mailman School, Columbia University, New York, NY.

${ }^{2}$ Henry Blackburn, Mayo Professor, Emeritus, School of Public Health and Medical School, University of Minnesota, Minneapolis, MN.

${ }^{3}$ Pekka Puska, Director General, National Institute for Health and Welfare (THL), Helsinki, Finland.
}

Corresponding Author Contact Information: Gerald M. Oppenheimer at go10@ columbia. edu; Brooklyn College and the Graduate Center, City University of New York and Center for the History and Ethics of Public Health, Mailman School, Columbia University, New York, NY. 
testing whether community-level models of risk factor modification through broad cultural change would demonstrate a reduction in the probability of disability and premature death from heart attack.

To tell the story of the community studies and to analyze outcomes, we focus on the Minnesota Heart Health Program and the Finnish North Karelia Project. From the North Karelia experience, we find that health promotion campaigns in communities at very high risk of disease, where the population lives in traditional patterns and considerable poverty and is also unsophisticated in health knowledge and behaviors, are more likely to achieve major and measurable population effects. We argue that as chronic disease rates rise globally, and CHD rates increase in lower- and middle-income nations, as they have over the past several decades, population-level prevention interventions have become particularly relevant. But it remains to be seen whether the international community, prodded by its member states, can successfully reproduce the urgency and agenda-setting that sparked the successful epidemiologic and public health interventions in the affluent countries in the decades after World War II.

Keywords: History of CVD epidemiology, epidemiology, coronary heart disease, chronic disease, non-communicable disease, Minnesota Heart Health Program, North Karelia Project, community studies, randomized controlled trial, primary prevention, community-based primary prevention programs

Recommended Citation: Oppenheimer GM, Blackburn H, Puska P. From Framingham to North Karelia to U.S. community-based prevention programs: negotiating research agenda for coronary heart disease in the second half of the 20th Century Public Health Reviews. 2012;33:450-83. (Please do not cite without permission of the authors)

\section{INTRODUCTION}

Following World War II, the United States Public Health Service made chronic disease, including coronary heart disease (CHD), the central focus of its biomedical program. It subsequently established new institutes of health for heart disease, arthritis, and neurological disorders, among others. In 1948, the newly formed National Heart Institute (NHI) responded to what its data showed as a rising tide of CHD by underwriting new approaches to the elucidation of chronic disorders. In the process, it funded the application of epidemiology, previously almost exclusively concerned with communicable disease, to study CHD. With federal encouragement, CHD epidemiologists enriched research designs, helped develop the randomized controlled trial, and played a pioneering role in chronic disease prevention at the individual and population levels. Government funding was critical to the evolution of this rich new science. A vibrant epidemiological imagination was able to capitalize on decades of national 
political commitment to the elucidation of chronic disease. Although no initial agenda were set, the development of CHD epidemiology developed, paradigm-like, as findings generated new resolvable problems.

Deeply influenced by its wartime experience of funding research, the U.S. government committed itself through its health agencies and tax dollars to study CHD, its cause and prevention, both intra- and extramurally. ${ }^{1}$ These included, as the initial sections of this article show, longitudinal studies meant to elucidate the relationship between well-measured clinical variables and subsequent CHD events. Consistent associations within and across populations, eventually reinforced by analyses of pooled data from multiple cohort investigations, demonstrated the existence of well-founded risk factors. But were these relationships causal? After substantial ambivalence, the federal government committed itself to an agenda of clinical trials to test that proposition. In addition, the results of the cohort studies generated a strong demand for a broader, population-wide approach, testing whether community models of risk factor modification would demonstrate a reduction in CHD morbidity and mortality.

Although historians have begun to examine the development of the cohort studies and subsequent clinical trials, the story of the community studies has received little attention. The latter will form the bulk of this article. Specifically, the principal investigators of two of these community projects, the Minnesota Heart Health Program (MHHP) and the Finnish North Karelia Project, will describe the conditions whereby an aggregate of local interests committed themselves to an agenda of broad cultural change to reduce the probability of disability and premature death from heart attack. In depicting his program, each of these investigators, Henry Blackburn and Pekka Puska, respectively, brings his unique voice and experience.

\section{THE FORMATION OF AGENDA: CORONARY HEART DISEASE COHORT STUDIES}

By the early decades of the $20^{\text {th }}$ century, mortality data revealed that chronic non-infectious disorders such as cardiovascular disease (CVD) and cancer had become the leading causes of death in affluent cultures like the U.S. Along with insurance companies and private foundations, the federal government, through the U.S. Public Health Service (PHS), pioneered morbidity surveys that demonstrated the rising burden of chronic illness and disability. ${ }^{2}$ These results were deepened by the National Health Survey, conducted by the PHS between 1937 and 1938, which found that approximately one in six Americans suffered from a disabling chronic 
disease or physical impairment; half of these individuals were under 45 years of age, often workers in their most productive stages of life. ${ }^{3}$

Although there was growing interest in understanding, treating and controlling such disorders during the interwar years, marked, for example by the creation of the National Cancer Institute (1937), national efforts to understand and control chronic disease, CHD included, accelerated after World War II.

In the early postwar years, epidemiology's aim remained primarily the study of infectious disorders. Within the PHS, Joseph Mountin, director of its Bureau of State Services, had recently created the Communicable Disease Center (later the Centers for Disease Control and Prevention), which would foster epidemiology's application to such diseases. ${ }^{4}$ But Mountin, a public health statesman and master of policy also struck a new direction. Strongly favoring disease control programs, initially developed for infectious disorders, he now advocated applying them to chronic diseases and insisted on an epidemiological component. ${ }^{5,6}$ In pressing for a heart disease control effort, Mountin initiated a process that evolved into the Framingham Heart Study. ${ }^{7}$

At that time, 1947, knowledge of what caused CHD was speculative. Clinical studies had implicated the possible role of dietary fat and elevated serum cholesterol in the development of an underlying atherosclerotic process. ${ }^{8}$ There was also evidence that serum lipid levels might be altered through dietary modification, an argument that environmental factors both caused and could possibly modify the risk of CHD., ${ }^{9,10}$ Based on mortality experience, insurance actuaries and clinicians suggested other determinants such as race, family history, age, sex, stress, blood pressure, smoking and alcohol consumption. ${ }^{11,12}$ Finding the etiology of CHD was of increasing importance as the weight of heart disease on mortality became a matter of grave concern. Employing the most inclusive category of death certification, cardiovascular-renal diseases, federal statisticians showed the death rates rising since the early 1920 s, almost exclusively in white males. ${ }^{10,13}$ By midcentury, they estimated that arteriosclerotic heart disease accounted for more than 22 percent of mortality, making it the leading cause of death. ${ }^{14}$

During 1947 and 1948, its first years, Mountin's Framingham Study was subject to a number of internal disputes, both personal and scientific. The dual nature of the study created a tension as to its purpose, only resolved when the control program was split from the epidemiological study and relocated to Newton, Massachusetts. ${ }^{7}$ In addition, precisely how epidemiology could be applied to CHD was a source of debate among the Framingham leadership. Unfortunately, Gilcin Meadors, the Public Health 
Officer selected by Dr. Mountin as principal investigator, had sparse experience in fielding an epidemiological study; he ended by creating a design that included variables difficult to measure with precision, a short longitudinal horizon of five to ten years, and little indication as to how the data collected would be analyzed., ${ }^{7}$

The eventual success of the Framingham Study was due, in part, to the agenda of another veteran of the PHS, Cassius Van Slyke, the first director of the NHI, established in 1948. At his insistence, Dr. Mountin reluctantly transferred his study to the NHI the next year. Like Mountin, Van Slyke was interested in applying epidemiology to chronic disease and argued that research like Framingham should be integral to the Institute he headed. In the decades that followed, the NHI funded a substantial number of other longitudinal investigations proposed by independent investigators in an effort to measure the incidence of and risk factors associated with CHD in various places and across classes of race, ethnicity and gender. These included cohort studies in Minneapolis, Albany, Los Angeles, Honolulu, Puerto Rico, Evans County (Georgia), and, later, in the cross-cultural Seven Countries Study.

Van Slyke directed his newly hired chief of biometrics, Felix Moore, to redesign the Framingham Study. Moore, a quantitative sociologist, brought to Framingham a talent for applied statistics, expertise in writing and scaling questionnaires, and the rigor of years of research work within the federal government. ${ }^{16}$ During Framingham's first year under the NHI, he was probably the principal architect of its scientific transformation. ${ }^{17}$ With Meadors' assistance and under Van Slyke's critical eye, Moore redesigned Framingham into a 20-year study of individuals, initially free of arteriosclerotic disease, selected randomly from the town's residents, both male and female, 30 to 59 years of age. Because Moore underestimated the refusal rate among those randomly selected, he and Meadors had to supplement the study with volunteers; ultimately comprising 14 percent of the cohort study's 5,127 participants, they were found to have identical characteristics to the randomly sampled. The baseline variables initially chosen by Meadors were also reexamined. After some debate, serum cholesterol level was included, as were body weight and blood pressure and the consumption of alcohol and tobacco. From the study's start, clinical variables predominated, with little focus on psychosomatic, constitutional, or sociological determinants of heart disease, areas Meadors had included in his previous designs. ${ }^{18}$

Under Van Slyke and his successors, the NHI continued Framingham as an intramural study for almost 20 years. But important results emerged 
surprisingly quickly. By 1956, the study's principals, Thomas Dawber and William Kannel, reported that atherosclerotic heart disease was significantly associated with age and male sex. In men 45 to 62 years of age, for whom sufficient data existed, heart disease incidence was correlated with hypertension, hypercholesterolemia and obesity. ${ }^{19}$ Framingham's findings were corroborated by heart studies in Albany and Los Angeles (also supported by the NHI). Over the next decade, these cohort studies, and another in Minneapolis headed by Ancel Keys and funded by the PHS, would extend their findings. In 1960, for example, Framingham and Albany, combining data to achieve greater statistical power, demonstrated a significant association and dose-response relationship between cigarette smoking and myocardial infarctions and heart disease-related deaths. ${ }^{20}$

The agenda of the NHI, like that of the National Cancer Institute, included the formation of a cadre of superb statisticians to support the epidemiological work. By 1968, the Framingham study had published its first 66 articles, the start of a cascade of over 2,000 peer-reviewed pieces. This rate of publication in a variety of journals, well beyond that of other contemporary cohort investigations, assured Framingham's prominence. As an intramural study of the NHI, its principals had a close working relationship with, in addition to Moore, statisticians Jerome Cornfield, Harold Kahn, and Tavia Gordon. They in turn, responding to analytic issues, developed important new statistical techniques, for example, those required to control for and summarize the multiple intercorrelated variables (more than 80 per Framingham participant) collected by cohort studies. ${ }^{21}$

\section{EQUIVOCAL COMMITMENT: THE EARLY RANDOMIZED TRIALS OF HEART DISEASE RISK FACTORS}

The early cohort studies continued to show a consistency of results across different populations. They also found that the presence of more than one "risk factor," a term newly coined in 1961, appeared to significantly raise the probability of CHD. ${ }^{22,23}$ In addition, epidemiologists learned that blood pressure and serum cholesterol level did not appear to have a cutoff below which individuals were without risk of the disease. Consequently, according to contemporary epidemiologists, almost every (male) U.S. adult was a potential heart patient. With no effective CHD treatment available, researchers argued that physicians, harnessing the new epidemiological evidence, should act to lower their patients' risk of CHD morbidity and mortality. 
Despite the growing evidence and the advocacy of epidemiological researchers, many physicians remained skeptics. They differed among themselves over the importance of treating essential hypertension, usually acting when it was very high or underlying organic damage was evident. They remained uncertain as well whether blood cholesterol level affected CHD, a question linked to the debate over the pathogenesis of atherosclerosis. ${ }^{24}$

Did any of the designated risk factors have a causative role in development of CHD? There was no direct evidence that reducing levels in those with high blood pressure, serum cholesterol or weight would lower CHD rates, producing outcomes similar to individuals with life-long lower numbers. To go beyond these natural limits of observational studies, epidemiologists, particularly those with experimental backgrounds like Ancel Keys and Jeremiah Stamler, and clinical researchers like Irvine Page, looked to controlled clinical trials for an answer. In doing so, they turned to the NHI for support.

The initial response of the National Institutes of Health (NIH), at least through the 1960s, was equivocal. In the late 1950s and early 1960s, it was unclear to scientific researchers and federal bureaucrats whether such experiments, using human populations, could be successfully engineered and completed. No one knew how well the quotidian consumption of food, medication or exercise could be accurately measured through long trials lasting five or more years. It was also unclear whether cadres of clinical professionals across multiple study sites could be socialized into researchers willing to follow the discipline of a common protocol. The question remained whether the results of such studies would be accepted by doctors and patients, ostensibly their ultimate consumers. Finally, politically powerful scientists involved in laboratory and traditional clinical research, already suspicious of it, feared the investment of NHI dollars in clinical trials might put their own funding, status and scientific goals at risk. ${ }^{8}$

In the early 1960s, the NHI itself had little experience with randomized controlled trials (RCTs), particularly cooperative trials at multiple centers. The Institute had previously given statistical assistance to an international trial of cortisone, aspirin and ACTH in the treatment of rheumatic fever and its consequences. ${ }^{25} \mathrm{Had}$ it been inclined, it could have looked to two controlled trials in progress, both initiated in 1959, of dietary change (reduced saturated and increased polyunsaturated fats), subsequent serum cholesterol levels, and heart disease events, namely the Finnish Mental Hospital Study and the Veterans Administration Domiciliary Study. ${ }^{26,27}$ Those studies were, however, limited to two facilities or one, respectively. 
Over the course of the decade, despite its inexperience, the NHI produced two significant trials. The first, the Diet-Heart Study, initially undertook the seemingly impossible task of testing the "coronary-genic" effects of the contemporary American diet. Prior to fielding a full trial, the principal investigators proposed, and the NHI approved, a two-year feasibility study across six research centers, commencing in 1962. Its primary study design was a randomized, double blind, controlled trial using special commissarysupplied, industry-prepared foods packaged to be indistinguishable, despite different fatty-acid composition for each arm. ${ }^{8}$ Its goal was to test whether diets lower in saturated fats and cholesterol would reduce serum cholesterol in the experimental arms, compared to controls consuming the typical American regimen. In addition, the feasibility study tested basic questions on which a full, more extended trial would hinge. Among them were: Would middle-aged men volunteer for a long-term study? Would they accept random assignment to a control group? Would they adhere to the experimental and control diets and thus lower their serum lipid levels? Was a double blind design workable? Would a non-blinded comparison using foods bought on the open market be adhered to and as effective in lowering serum cholesterol? And at what rate would volunteers drop out of the study? ${ }^{28}$

Although the two-year trial answered those questions in the affirmative and reported that the average cholesterol level for those in the experimental groups decreased by more than 11 percent by the end of the first year (a decline appreciatively different from baseline than that of the controls), the NHI refused to field the full study. ${ }^{8}$ Reasons for rejection included the large number of participants (between 49,000 and 219,000 depending on the endpoints used) and the high cost of such an investigation. In addition there was continued skepticism as to whether participants would remain compliant with the protocol over the course of a five-year study. There is also evidence that members of the primary advisory group to the director, the National Heart Advisory Council, composed primarily of prominent clinical and laboratory researchers and academic physicians with little knowledge and appreciation of population-based research, believed that the solution to CHD lay in their more traditional approaches. The final quietus occurred in late 1967, when an NHI review panel, headed by Edward Ahrens, a metabolic and clinical researcher at Rockefeller University, cautioned against the full study. ${ }^{29}$ A conclusion recommending against a national diet heart trial was made by another review panel that Ahrens chaired in $1970 .^{30}$

The second significant trial fielded by the NHI was the Coronary Drug Project (CDP), a randomized, double blind, secondary prevention study. ${ }^{31}$ 
This trial, assayed the effect of cholesterol-lowering agents on rates of CHD events in men with heart disease. As a more traditional study, it garnered more support within the National Heart Advisory Council than had the Diet-Heart Feasibility Study. Its clinical outcomes, however, were deeply disappointing. Early on, three of the regimens, two doses of estrogen and a thyroid extract (dextrothyroxine) had to be discontinued when they were associated, respectively, with a raised rate of nonfatal heart attacks and excessive mortality. Another drug, Clofibrate, achieved no significant effect on the rate of adverse coronary outcomes but was associated with higher risk of thromboembolism and angina pectoris. A fifth agent, niacin, appeared to have some advantages over the placebo; because it did produce sustained reductions in serum cholesterol and triglycerides without serious side effects, the study made cautiously limited recommendations for its long term therapeutic use.

What was remarkable about the CDP was the trial's magnitude-over 8,000 men and 53 study sites. The most successful outcome of the CDP, one might argue, was to develop an organizational model for administering large-scale cooperative trials, a model that became standard for the NHI. In summing up the results of the trial in 1975, Robert Levy, an expert on lipid disorders and director of the Institute, made that point. ${ }^{32}$ The CDP had demonstrated, he argued, that a multi-center clinical trial of CVD intervention was possible. Specifically, physicians, researchers and patients could be motivated to cooperate and to accept the discipline and constraints of a large clinical trial.

\section{INTEGRATING RANDOMIZED TRIALS INTO THE RESEARCH PROGRAM}

Levy's response mirrored a change in the Institute's agenda. The late 1960s had marked a policy period that epidemiologist Henry Blackburn has characterized as "The Pause." The rejection of both the Diet-Heart Study and a large multi-risk factor trial proposed by Jeremiah Stamler, the University of Minnesota's Henry Taylor, Michigan's Richard Remington, and a group of other experts, left the NHI at an institutional impasse after 1968. However, by the mid 1970s, the Institute pushed to formulate a new agenda in which RCTs were integrated into the research program.

Early in that decade, it appeared that the research position of the NHI was being superseded by other health organizations. Domestically, the Veterans Administration had initiated decisive RCTs of drug treatment for hypertension. Headed by Edward Freis, they demonstrated by 1970 that 
anti-hypertension agents could significantly lower blood pressure in men with diastolic levels of 90 through $129 \mathrm{~mm} \mathrm{Hg}$ and reduce hypertensionrelated morbidity ${ }^{33}$ Overseas, the World Health Organization promulgated a European Collaborative Trial of Multifactorial Prevention of Coronary Heart Disease in 1970 and physicians in Norway were planning what became the Oslo Diet-Heart Study, inaugurated in 1970..$^{34,35}$

It was in this environment that Theodore Cooper, Levy's predecessor as director, established a Task Force on Arteriosclerosis in 1970 to formulate a long-range plan "to remedy current inadequacies, and to establish new directions of inquiry" to prevent and control arteriosclerosis. ${ }^{30(\mathrm{p} .1)}$ Among the many recommendations in its final report was that the NHI commit itself to conducting clinical trials of the major CHD risk factors. It argued that "the likelihood is high that a causal relationship exists between risk factors and the development of arteriosclerosis, and that a reduction in risk factors will decrease the incidence of the clinical manifestations of arterioscerosis." ${ }^{30(p .20)}$ Although the task force advised against a national diet-heart trial, it stressed the need for multifactor, primary prevention trials using individuals with multiple elevated risk factors as preliminary to any action plan. "These trials will have the merit of demonstrating," the report read, "whether or not intervention can prevent the complications of human arteriosclerosis since this is the crucial question as yet unanswered by direct experiment." $30(\mathrm{p} .22)$

In his George Lyman Duff Memorial Lecture the next year, Dr. Cooper spoke about the emerging arteriosclerosis policy at the NHI. In his farranging talk, Theodore Cooper recognized that all facets of biomedicinelaboratory, clinical and population based-produced vital concepts and important congruent data. ${ }^{36}$ As he made clear in his lecture, he endorsed the Task Force's strong recommendations for clinical trials "to study mechanisms and...test the preventive potential of practical public health measures. ${ }^{36}$ Cooper called for a trial to test the relationship between blood pressure control and a reduction in CVD in various populations. He asked for a trial to test the practicality of broad risk factor reduction through a multifactorial clinical trial that included programs for smoking cessation, blood pressure control and bringing down serum cholesterol. Finally, he recognized the need for a trial of the lipid hypothesis, using participants with elevated blood lipids.

Over almost 15 years, the Institute fielded trials already outlined by the Task Force and Theodore Cooper. In 1971, the renamed National Heart and Lung Institute funded the Hypertension Detection and Follow-up Program (1971-1982), a large, multicenter trial providing anti-hypertensive drugs to patients with diastolic levels of 90-114 mm Hg. This was followed almost 
directly by the Multiple Risk Factor Intervention Trial (MRFIT, 1972-1998), a large study of healthy men with elevated risk factors for coronary heart disease, and the Coronary Primary Prevention Trial (1973-1984), a test of the lipid hypothesis using the cholesterol lowering drug cholestyramine. Participants in the latter were men with primary hypercholesterolemia.

The MRFIT found no significant difference in disease experience risk factor reduction between those in the intensive special intervention program, who received hypertension treatment, dietary advice and smoking cessation counseling and controls who continued to receive their usual medical care. ${ }^{37}$ Risk factor levels in the special intervention group did decline: cholesterol levels somewhat less than expected but smoking cessation was substantial and the reduction in diastolic blood pressure exceeded the study's goal. But those in the usual care group also experienced sizable, albeit smaller changes in all three factors, contrary to the researchers' initial expectation of no significant decline. Why the controls registered these unanticipated results was speculated upon at the time. Among reasons given, none mutually exclusive, were that voluntary trial participants, regardless of their randomized placement, may have been more conscious of health and open to change; perhaps participating in a trial for those at high risk for heart attacks may have had the effect of precipitating behavioral modification; also possible was that new heart healthy popular education and the ministrations of their own physicians may have been determinant, so that the statistical power of the trial was weakened by cultural transformation. Each of these speculative suggestions raised questions about the limitations of RCTs of intervention on lifestyle.

The first and third of these primary prevention trials, however, had important implications for "the preventive potential of practical public health measures". The Hypertension Detection Follow-up Program demonstrated the efficacy of drug therapy in men with mild hypertension (90 to $104 \mathrm{~mm} \mathrm{Hg}$ ), enlarging the pool of those eligible for such treatment. ${ }^{38}$ And the outcome of the Coronary Primary Prevention Trial was interpreted by the Institute to support a causal relationship (thereby relieving the now National Heart, Lung, and Blood Institute (NHLBI), of its dilemma) as well as a campaign to lower blood cholesterol in the American population. ${ }^{39}$ Whereas the first wave of controlled trials, like the Diet-Heart, did not succeed in having any clinical impact, this second wave decidedly did. Conversely, that impact helped sustain the luster of that expensive piece of technology, the RCT.

In the decade of the 1970s, a number of epidemiologists began to argue in favor of an alternative approach to the prevention of heart disease, 
conceptualizing it as a population or public health problem. Clinical trials, as just described, were aimed at "high risk" individuals. So too was the clinical medicine of the period. Clinical trials required years to complete and analyze. But cohort studies like Framingham and the Seven Countries Study, headed by Ancel Keys and his colleagues abroad, had already demonstrated reliable associations between risk factors and CHD; so did the cumulative evidence of the American Heart Association Pooling Project. ${ }^{40}$ Why not initiate community demonstration programs that aimed at preventing CVD by lowering a population's risk factors? Would not transforming the culture of a community be more effective than looking to change individual behaviors? Given evidence that risk factor modification was safe, why not begin sooner rather than later? Commitment to such community prevention trials began in a number of countries under varying circumstances, and, with the exception of the early Stanford Three Community Study, led by John Farquhar, somewhat later in the U.S. than in Europe. ${ }^{41}$

In the U.S., community-based trials, with the exception of John Farquhar's study, were held in abeyance until the NHLBI had fielded significant RCTs of CHD risk factors. The Institute only committed itself to community trials in the early 1980 s, in part goaded by congressional pressure and by the example of apparently successful programs in Europe, the North Karelia Project in particular.

Once such demonstration projects became part of NHLBI's research agenda, it funded trials in California, Rhode Island and Minnesota. The next section of this article belongs to the voice of Henry Blackburn, principal investigator of MHHP, the largest of the community prevention trials begun in the U.S. in the early 1980s. Already a veteran epidemiologist, long associated with the Seven Countries Study and RCTs like the CDP and MRFIT, and an early advisor to the North Karelia Project, he brought the thread of all these experiences to the initiation of the MHHP.

The North Karelia Project, one of the first community-based trials, followed upon consistent findings by a component of the Seven Countries Study, the Finnish East-West Project, that North Karelians had the highest heart attack rates in the world. Community apprehension at multiple levels about such devastation precipitated a strong political response. The measured result was a coordinated province-wide demonstration and research agendum drawing on government, scientific and voluntary organizations, the media, food producers, clinicians and citizens of the region. In the final section, Pekka Puska, the project's principal investigator from its inception in 1972 through 1997, describes the North Karelia Project, its origins and consequences, both national and international. 


\section{COMMUNITY PREVENTION TRIALS INTRODUCED: THE MINNESOTA HEART HEALTH PROGRAM}

The idea of community trials or demonstration programs of CVD prevention in whole populations was a major leap of logic. It arose in the late 1960s from independent thinking among people who were, nevertheless, communicating. It was first implemented in the early 1970s in Finland and at Stanford University. The MHHP had the same intellectual origin as the North Karelia Project; that is, in the large population differences in coronary disease rates associated with culture and diet that were documented for the first time in 1970 by the Seven Countries Study of Ancel Keys and an international team. ${ }^{42}$

As already indicated, the leap of logic to community programs was intended, by the several pioneer groups involved, to by-pass an academic requirement of that time for experimental "proof" of causation by controlled trials among randomized individuals. The originators of the populationwide approach accepted as sufficient for action the sound observational evidence then accumulated about the association of risk factors and actual risk, plus the evidence from clinical and laboratory studies congruent with causality for those risk factors. The different population rates and risk distributions among populations, combined with the experimental evidence that it was feasible and safe to modify personal risk characteristics by hygienic and pharmacologic interventions provided the rationale for the population-wide strategy. The object then became to carry out interventions with adequate designs for their evaluation. ${ }^{* 43}$

Those holding this population view also questioned whether "proof" of cause by clinical trials was as strong, binding, or essential to scientific inference as purported; whether trial results from select affluent groups were generalizable to the whole population, and whether trials were more relevant to public health decisions than consistent associations found among "natural experiments" among contrasting traditional cultures. For the investigators at origin, these challenges of "proof" arose explicitly in

\footnotetext{
* The biologic concept behind these efforts came from evidence that mass adult diseases in affluent societies are the result of ubiquitous and powerful environmental factors acting on wide population susceptibility. The environmental factors are predominantly culturally determined, socially learned behaviors. The population susceptibility is thought to be a human evolutionary legacy. Then, if whole communities are at excess risk of CVD, focus solely on the portion of highest risk appears to be a useful medical part of a community-wide prevention approach but is insufficient to interrupt or prevent epidemics. The several education strategies planned for the community studies were assumed to be complementary, perhaps synergistic.
} 
the Panel on Causation of the Makarska Conference on Mass Field Trials in the Prevention of Coronary Heart Disease held in Yugoslavia in 1968. ${ }^{44}$

In any case, the story of the North Karelia community project has been well told, both later in this article and elsewhere ${ }^{45}$ Minnesota's communitywide research agendum came from personal experience in the early years of the Seven Countries Study and encounters with the local activism in East Finland precipitated by that study's findings. In East Finland, following the first survey in 1959, a bewildered delegation from the friendly populace presented, immediately after it was announced that their region boasted the world's highest heart attack rates and had the world's highest blood cholesterol levels! Following the 1964 survey, the local queries were more pointed and agitated: "Why us?" they asked. Then in 1969, with the record findings again verified, the confrontation became distressed. The people's representatives were demanding that we help "do something about this terrible rate of heart attacks among us!"

Pekka Puska has described in the following section how this unique regional situation was channeled into community action, importantly through the guiding hand of Finnish physician, Martti Karvonen. Finally, in fall 1971, Karvonen convened a WHO expert review group on the North Karelia Project plan. It included Jeremy Morris, social epidemiologist of London, and me. There we witnessed the community organizing for the challenge of its shocking and exceptional medical status.

I came away from that Finnish scene motivated to implement a community model of CVD prevention for Minnesota. There would be, however, a sizable delay in its implementation as clinical trials and the more academic pursuit of the touted experimental "proof" took precedence.

A generation of randomized clinical trials of CVD prevention was initiated in fall 1971 with a national research policy announced by the National Heart and Lung Institute's director, Theodore Cooper, at the American Heart Association Scientific Sessions. It was at the same moment that North Karelia and the pilot Stanford community programs got under way. The new U.S. policy sought to satisfy the pressure on NIH from the vocal preventionist community calling for some public policy on heart attack prevention. It was to replace the proposal that the NIH had rejected in 1969 of a single-factor National Diet-Heart Trial, a study greatly feared by some in academia and by NIH staff because of its huge cost. It was also to counter the threat to U.S. leadership in CVD prevention by trials just undertaken in the United Kingdom, continental Europe, and Scandinavia. Thus, the tension was great. It was time something was done. 
Those investigators who participated in the 1968 conference on Mass Field Trials in the Prevention of Coronary Heart Disease, held in Makarska, Yugoslavia, along with a larger informed scientific community, had insisted for several years that if proposed public programs in prevention were unacceptable to the academy and the bureaucracy then "definitive trials" were the only rational alternative. ${ }^{46} \mathrm{As}$ it turned out, we were quickly forced to "put up or shut up" and to help plan and carry out those complex, tedious trials, which many of us thought unnecessary in the first place. In that 1970s atmosphere, there would be trials, or nothing at all, for preventing heart attacks.

Starting in 1972, the NIH funded a series of prevention trials into which virtually the whole of the U.S. CVD research community was drafted: the Hypertension Detection and Follow-up Program and other clinical trials already described, as well as various pharmaceutical approaches to blood pressure and blood lipid level lowering in patients and high-risk recruits and in whole communities. It was a frantically busy period during which the CVD prevention community was vastly expanded, as were its experience and competence.

By 1978, when we in Minnesota were over the hump in these trials, we were finally able to submit to NHLBI the first version of the proposed MHHP. Meanwhile, much had transpired on the national scene. Stanford University had completed its pilot Three Community Study with promising results and proposed a sophisticated Five City Study. A Memorial Hospital group in Rhode Island proposed the Pawtucket Heart Health Program. In the same period, the dramatic decline in age-specific death rates from CHD was recognized and then detected widely among Western industrial countries. On the international research scene, Gothenburg University investigators in Sweden were intervening on multiple risk factors and WHO was coordinating the European Multiple Risk Factor Trial in Industry and launching comprehensive community control programs in chronic diseases on the continent.

On the other hand, much had not changed in the status of "proof" among the scientific leadership or in its priorities for obtaining ever-more evidence before recommending wide CVD prevention efforts. And as was usual, an elite of clinical and laboratory science leaders largely set those priorities and felt that they had already moved quite far conceptually in accepting and advancing the science of preventive trials.

Early results from those trials in CVD appeared in the late 1970s and were mixed. Much of the leadership, therefore, was still not ready to make public recommendations on diet or lifestyle or on medical interventions 
other than anti-hypertensive drug therapy among high-risk men. "We simply don't know enough to make recommendations to the public," was the usual iteration.

The idea of community demonstrations of health promotion remained foreign, as well, to those who controlled national research policy. An extended running-in period would be needed for NIH to develop competent review for such new-fangled ideas as "quasi-experimental" community trials of CVD prevention!

\section{COMMUNITY TRIALS: AN INSTITUTIONAL NICHE IS FINALLY CREATED}

A niche for community trials, along the NIH spectrum of laboratory, clinical, and population research and their applications, was eventually established during the early 1980s leadership by Robert Levy at NHLBI, where forward policy and political will for prevention surpassed that of all the other institutes. Levy confided to some of us that his courage in maintaining this view, against a large scientific community opposed to such use of funds, came from the ardent appreciation expressed by the United States Congress during his regular testimony before its committees. Thus, NHLBI was early and unique in translation and application of scientific endeavor to the public domain. It was something the Congressmen could take home, something which "value-free" basic science was not.

Eventually, three major U.S. community programs in CVD prevention were funded, at Stanford, Minnesota, and Rhode Island. At the outset, each had similar theory-based approaches but different strategic emphases and collaborative structures. ${ }^{47-49}$

\footnotetext{
* I surmised at the time that a quintet of mature investigators with a population view of the origins of mass diseases might accurately and efficiently assess the design and management potential among proposals for community demonstrations. Instead, NIH was obsessed with providing specialists for each component of such programs, thus requiring cardiologists, nutritionists, multiple risk factor experts, behavioral scientists, statisticians and data managers, professional education experts, community organizers, screeners, communications specialists, school and youth program experts, etc.). This policy to cover all bases resulted in project evaluations by as many as two dozen narrowly focused experts, each jealous of his field and highly suspicious of generalists and "docs" leading the community efforts! A distribution of their review scores inevitably yielded an equivocal priority ranking rather than a fundable score.
} 


\section{THE MINNESOTA HEART HEALTH PROGRAM IS REALIZED}

Minnesota strengths were considerable in the late 1970s for such a major community undertaking. We had several decades of experience sampling the community and recruiting from it for various interventions: the Minnesota Business and Professional Men Study, the Coronary Drug Project, MRFIT, the Lipid Research Centers Prevalence Study, the Hypertension Detection and Follow-up Program (HDFP), and the 1979-funded Minnesota Heart Survey (MHS) of hospital surveillance and population-based risk factor surveys. From the mid-1970s, for MRFIT and its offspring studies, we had recruited to our department virtually all the staff expertise required for community interventions, excepting community organizers and media experts. These we soon found on our campus, with enthusiastic involvement from the Schools of Social Work and Journalism.

Passing over the obvious hurdles and complexities of the MHHP proposal to NIH, we had but to put pen to paper with our design for intervention and evaluation. By 1980, NIH peer-review had sufficiently "matured" that our effort was approved on a second go-round of review, as were those of Stanford and Rhode Island. Minnesota's long experience with the "community-as-laboratory" led to what we thought a strong and balanced design for intervention and evaluation; strong, in that it involved sequential entry into three progressively complex communities and matched comparison towns (thus, internal and external "controls,") and because it gave the community major authority in program direction; balanced, in that we assumed each intervention component was equally important among screening and direct education, community organization, and mass communications. ${ }^{49,50}$

At the outset, all three programs borrowed from social learning, network diffusion, and social marketing theory to bring their messages to individuals and the entire population of the educated towns. Stanford's emphasis was on mass media interventions; its direction was top-down. Pawtucket (Rhode Island) utilized almost entirely existing community structures for its intervention. These three models, as independent, investigator-initiated grants, would have made useful comparisons of intervention and management strategy, but they were not to survive as independent entities. Almost at once, NIH, based on its perceived fiscal responsibility, sought closer oversight over its huge investment in the three programs and imposed an NIH-led Community Coordinating Committee (CCC). With repetitive meetings, updates, and nudging by the Committee, the strengths and ideas of each were assimilated by the others. The three soon became more and more like each other. ${ }^{51}$ 


\section{MHHP DESIGN AND OPERATION}

Clearly, much legwork in the several communities was required to make our proposal feasible and convincing, and we underwent two rigorous NIH site visits from the earlier- described, over-manned groups of narrow specialists. We considered that several of our concepts for the intervention cities of Mankato, Fargo, and Bloomington were unique, over and above the three, paired communities design. For example, each had programs in its own name rather than in the name of the University of Minnesota; each its own director and board, community organizers, and locally appointed task forces (e.g., school, anti-smoking, physical activity, restaurant and supermarket programs). They relied on the Central Executive at the University for advice and funding and on the University Media Unit for preparation and provision of small and large media.

Meanwhile, the University faculty and staff had its matrix organization with an executive committee and an oversight board of national experts in community organization, communications, sampling, design and analysis, behavioral theory, and social marketing. All systems functioned reasonably well throughout.

A main problem in direction during MHHP intervention was the long lag time to receive results of evaluation (aside from the appropriateness at all of evaluation of physical end points), and the difficult decision-making to innovate and introduce timely new strategies, versus redoubling efforts for an extant strategy that seemed to be lagging! The five-year plan left little time for extemporaneous corrections.

\section{MHHP RESULTS}

Surveillance for evaluation of MHHP involved several programs: 1. A recurring cross-sectional community risk factor survey in both educated and comparison towns as the more stringent method to explore community time trends in risk; 2. Successive measurements of the same CVD risk factors in cohorts participating in intervention programs, such as the screening clinics in educated communities; 3 . Surveillance of coronary heart disease events in hospitals of all six communities; and 4.Various measures of program "penetration" and impact, including numbers of special program participants.

A number of MHHP cohorts showed significant measurable changes in risk factors or behavior during and after the formal intervention period. The cross-sectional risk factor surveys, on the other hand, indicated that both 
educated and comparison communities experienced favorable risk trends. We found little solid evidence that the intervention was more influential than on-going changes in society, represented by the comparison towns. Stanford and Pawtucket community studies found pretty much the same in their designed cross-sectional comparisons. Each study involved many campaigns and programs touching many thousands of people and achieving favorable behavioral and risk factor changes measurable in the cohorts, but the net cross-sectional differences in the physical measures were small and statistically not significant. The small number of cities in each study, and in all of the studies together, was also a limiting factor for analysis.

Individual program components were documented to be more and less well embraced and more and less apparently effective; for example, in MHHP, both hypertension control and physical activity levels showed good trends and school programs had measurable effects on delaying the age of taking up smoking and on healthy eating patterns at the school. Much was learned about how to enter and involve communities in health promotion, about specific effects of risk screening and direct education, and of media, about food demonstrations and lotteries, about community organization, and about the relevance of the various theoretical models of behavioral change, medical and population strategies.

Long after the intervention period, analysts from each of the three NIHsponsored U.S. efforts pooled the risk factor results from six educated and six comparison communities and summarized the overall contributions, here paraphrased..$^{52}$

The studies clearly documented major risk and behavioral changes during the period of the 1980s when large health changes were underway nationally, and they identified subgroup disparities in which some benefitted and others were little touched.

They devised and tested in diverse communities (but did not formally compare), a variety of interventions that were rapidly and widely adopted by groups in other community programs and for other issues such as the prevention of cancer, osteoporosis, diabetes, and obesity. (MHHP, for example, demonstrated that in the last years of the study the control towns "caught up" with the effects of early screening and education for cholesterol lowering in the educated towns.)

They summarized: "Favorable secular trends in both health promotion and risk factors made it difficult to demonstrate a specific intervention effect in the three U.S. trials." Finally, they concluded that the a priori hypotheses (20\% change difference in risk) of the U.S. studies were optimistic, "especially for community-based interventions, where even small reductions at the community level can have a significant impact on the public's health". ${ }^{52}$ 
The American experience with CHD community-based interventions owed a great deal to the creative epidemiology of the post-war decades, including the cohort studies and controlled clinical trials. It was also in debt to the earliest major CHD community project and evaluation program, one that stemmed directly from cross-cultural cohort studies organized in the U.S. and abroad. In the next section, Pekka Puska describes that project as it unfolded in Finland.

\section{INTRODUCTION: THE NORTH KARELIA PROJECT: FROM CHD EPIDEMIOLOGY TO PUBLIC HEALTH}

Before World War II, Finland was a very poor country, depending primarily on forestry and agriculture (mainly small dairy farms). Public health was dominated by infectious diseases, like tuberculosis, and high child and maternal mortality. After the war, as the standard of living gradually increased, infectious diseases were brought under control and public health improved. But new, chronic disorders emerged. Rates of CVDs, especially $\mathrm{CHD}$, and lung cancer rose. Deaths from these diseases became common, even among quite young men. The popular assumption was that these diseases were related to hard work and aging.

In the medical community, CHD as a diagnostic entity had already become firmly established before the war. In 1947 a young demographer, Väinö Kannisto, published his doctoral thesis on mortality in Finland, pointing out that mortality in eastern regions of the country had been higher than in the West since the $19^{\text {th }}$ century, and that heart disease deaths there were particularly common. ${ }^{53}$ In 1953 , Helge Honkapohja, who subsequently became head of internal medicine at the North Karelia Central Hospital, published an article in which he observed that by 1951, CHD had passed tuberculosis in number of deaths. Somewhat later, statistics showed that heart disease rates for Eastern Finland were the highest reported in the international tables.

Coincidentally, in the spring of 1954, Finnish Professor Martti J. Karvonen visited the Laboratory of Physiological Hygiene of the University of Minnesota in Minneapolis and met its director, Ancel Keys. Since 1948, Dr. Keys had propounded his hypothesis on the chain of causation: dietary fat-high blood plasma cholesterol—atherosclerosis and its clinical manifestations in the cardiovascular system..$^{54}$ This encounter provided the stimulus for the two leaders to join forces in 1956 to launch the first EastWest study of coronary risk factors in Finland. 
That cross-sectional study appeared to support the cholesterol hypothesis: dietary intakes of saturated fats, as well as serum cholesterol values, were high by international standards, and both were higher in the East than the Southwest. ${ }^{55,56}$ This led to a longitudinal study of two contrasting populations of men in Finland, aged 40-59 years at entry in 1959. As a component of the Keys-initiated Seven Countries Study, these cohorts of men were examined at five-year intervals for ten years and then followed to the present time.

\section{START OF THE NORTH KARELIA PROJECT}

The Finish East-West findings over the first decade of the Seven Countries Study, demonstrating higher rates of CHD in the East, buttressed by published health statistics and the personal observations of people in the affected population, increasingly heightened popular concern. In January 1971, the representatives of the Province of North Karelia, the eastern site of the East-West study, signed a petition to the Finnish government requesting urgent assistance to reduce its high CHD burden.

Subsequently, under the encouraging guidance of Professor Karvonen, the Finnish Heart Association set up a planning group, including several Finnish experts. This led to a planning seminar in September 1971 in North Karelia, with several international WHO experts in attendance, among them Henry Blackburn of Minnesota and Jerry Morris of London. The meeting outlined the main principles of the North Karelia Project and recommended further steps: setting up the project organization, appointing the project director/principal investigator and selecting the core project team.

The project team consisted of young Finnish doctors and social scientists, several of whom were veterans of radical student movements. They devoted their energy to fundamental change in the public health of North Karelia, based on new epidemiological findings barely mentioned during their medical studies. So radical was their approach and so limited their scientific experience, that the team at first faced opposition and suspicion from many sources: scientific, cardiological, political, administrative and economic - and particularly from the dairy industry. But when in 1973, the Ministry of Health turned to Geoffrey Rose, professor of epidemiology at the London School of Hygiene and Tropical Medicine as an outside consultant, he was quite positive, finding that the Project was "well designed in order to give a good chance of success" in testing "whether (and how) coronary risk factors can be controlled in the community". 
During the early years, the North Karelia project had several influential supporters within Finland who helped assure its continuation. In addition to Professor Karvonen himself-whose academic standing was matched by his influence as Surgeon General of the Army - they included Leo Kaprio (Regional Director of WHO/EURO), Leo Noro (Director General of the National Medical Board), and the powerful governor of North Karelia, Esa Timonen. And, of course, the population was very interested and participated as well, although making lifestyle changes was not easy.

During the planning phase, the young leadership of the project was faced with the enormous challenge of lowering such high CHD mortality rates. The common belief in contemporary medical circles was that the success of primary prevention was uncertain. The North Karelia study team thought otherwise. For the team it was obvious that clinical treatment, often too late, dealt with consequences-not causes. The team realized that the big potential for CVD control was in primary prevention, while in contemporary medical circles, the possibility of prevention was generally considered uncertain. The results of Framingham and other studies were reviewed in light of the situation in North Karelia, where smoking among men was markedly common, median blood pressure levels were raised, and serum cholesterol levels were extremely high, reflecting a traditional diet very high in saturated, especially dairy, fat). The decision was made to target these risk factors in the provincial population to test whether their levels could be lowered, and with that, heart disease rates.

The next question for the Project was one of strategy, of how to influence health behaviors. It was also understood that to reduce disease rates in the population, working solely with individuals at "clinically high risk" was insufficient. A population-based approach was needed to reduce the overall high levels of risk factors in the population.

This then was the background to the "community-based approach" for prevention of CVDs for the North Karelia Project. So novel was the community approach in the early 1970s that a 1973 editorial in the International Journal of Epidemiology criticized it with the title "shotgun prevention. ${ }^{57}$

\section{PRINCIPLES OF THE NORTH KARELIA PROJECT}

Although the main concepts of the North Karelia Project-a community based, comprehensive intervention to reduce the population level of risk factors and an evaluation design - were clearly formulated at the outset, many concepts and strategies were developed during project implementation. 
The original aim was to carry out the comprehensive preventive intervention in North Karelia for a five-year period (1972-1977). From the outset, the Project was seen as a pilot study for an intervention that might be applied to all of Finland, as it was in 1977; at the same time, it continued in North Karelia as a national "demonstration" or "model." Its highly visible example presumably helped the national program to work.

\section{SUMMARY RESULTS OF THE NORTH KARELIA PROJECT}

The evaluation design and results of the North Karelia Project have been described in two summary monographs. ${ }^{58,59}$ During the initial five-year period, major changes were seen in diet; in addition, hypertension control was improved and smoking reduction reported among men. These and the associated changes in serum cholesterol and blood pressure levels continued in North Karelia on termination of the local intervention while major changes also took place in the rest of the country.

Table 1 shows the change in the targeted risk factors in North Karelia from 1972 to 2007, based on standardized surveys of representative populations. $^{60}$

Table 1

Main risk factors in North Karelia between 1972 and 2007 among men and women aged $30-59$ years

\begin{tabular}{c|c|c|c|c|c|c}
\hline & \multicolumn{4}{|c|}{ Men } & \multicolumn{3}{c}{ Women } \\
\hline Year & $\begin{array}{c}\text { Smoking } \\
(\boldsymbol{\%})\end{array}$ & $\begin{array}{c}\text { Serum } \\
\text { cholesterol } \\
(\mathbf{m m o l} / \mathbf{l})\end{array}$ & $\begin{array}{c}\text { Blood } \\
\text { pressure } \\
(\mathbf{m m H g})\end{array}$ & $\begin{array}{c}\text { Smoking } \\
(\boldsymbol{\%})\end{array}$ & $\begin{array}{c}\text { Serum } \\
\text { cholesterol } \\
(\mathbf{m m o l} / \mathbf{)})\end{array}$ & $\begin{array}{c}\text { Blood } \\
\text { pressure } \\
(\mathbf{m m H g})\end{array}$ \\
\hline $\mathbf{1 9 7 2}$ & 52 & 6.9 & $149 / 92$ & 10 & 6.8 & $153 / 92$ \\
\hline $\mathbf{1 9 7 7}$ & 44 & 6.5 & $143 / 89$ & 10 & 6.4 & $141 / 86$ \\
\hline $\mathbf{1 9 8 2}$ & 36 & 6.3 & $145 / 87$ & 15 & 6.1 & $141 / 85$ \\
\hline $\mathbf{1 9 8 7}$ & 36 & 6.3 & $144 / 88$ & 16 & 6.0 & $139 / 83$ \\
\hline $\mathbf{1 9 9 2}$ & 32 & 5.9 & $142 / 85$ & 17 & 5.6 & $135 / 80$ \\
\hline $\mathbf{1 9 9 7}$ & 31 & 5.7 & $140 / 84$ & 16 & 5.6 & $133 / 80$ \\
\hline $\mathbf{2 0 0 2}$ & 33 & 5.7 & $137 / 83$ & 22 & 5.5 & $132 / 78$ \\
\hline $\mathbf{2 0 0 7}$ & 31 & 5.4 & $138 / 83$ & 18 & 5.2 & $134 / 78$ \\
\hline
\end{tabular}

Source: Puska P, et al., $2009^{59}$ 


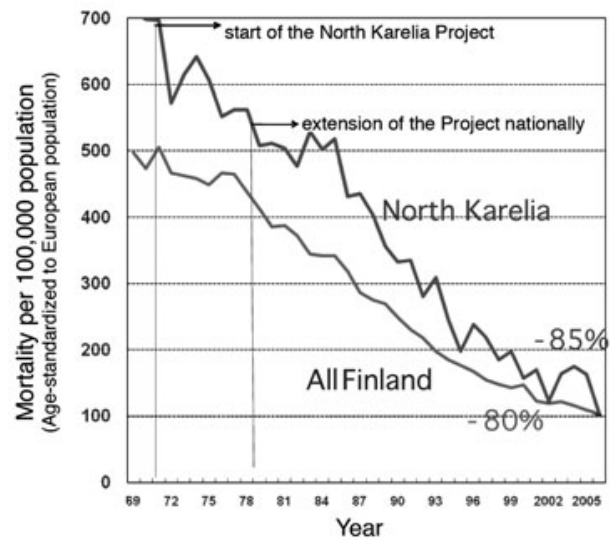

Fig. 1. Age-adjusted mortality rates of CHD in North Karelia and the whole of Finland among males aged 35-64 years from 1969 to 2006.

Source: Puska P, et al., $2009^{59}$

Figure 1 shows the reduction in age-standardized rates of the region's CHD mortality rates, the primary objective of the North Karelia Project. In 35 years, the annual age-adjusted CHD mortality rate among the 35-64 year-old male population in North Karelia declined by 85 percent. But there was also reduction in CVD rates as a whole, and in many cancers among men (especially tobacco-related), and in all causes of mortality for both sexes, (Figure 1, Table 2).

\section{Table 2}

Mortality changes among men in North Karelia from 1969-1971 to 2006 (per 100 000; age 35-64 years)

\begin{tabular}{l|l|l}
\hline \multicolumn{3}{c}{ Change in Mortality Rate From 1969-1971 to 2006} \\
\hline Mortality category & North Karelia & All Finland \\
\hline Cardiovascular & $80 \%$ & $75 \%$ \\
Ischaemic heart disease & $85 \%$ & $79 \%$ \\
Cerebrovascular stroke & $69 \%$ & $73 \%$ \\
Cancers & $67 \%$ & $53 \%$ \\
All causes & $63 \%$ & $56 \%$ \\
\hline
\end{tabular}

Source: Puska P, et al., $2009^{59}$ 
The relative decline in CHD mortality rates in North Karelia was clearly greater in the younger age groups, especially in men aged 35-44 (96\%), but it was also found in older men, 65-74 years of age (69\%). Nationally, moreover, during the project period (1972-1997), those in the 35-74 years age group experienced approximately 243,000 fewer deaths than estimated if mortality rates had stayed at the pre-program level. As a result of the improved adult mortality rates, the estimated life expectancy at birth in Finland rose from 66.4/74.6 years (males/females) in 1971 to $75.8 / 82.8$ years in 2006, and in North Karelia from 64/72 to 75/81.

Separate analyses have shown that the observed reductions in population risk factor levels can account for most of the decline in CHD mortality. ${ }^{61} \mathrm{Of}$ the single risk factors, reduction in serum cholesterol level had the greatest apparent impact. It is thus likely that most of the extraordinary decline in CVD death rates has been due to primary prevention. We have not documented, but presume that concurrent improvements in medical therapy have also contributed to the favorable developments.

\section{LESSONS FROM THE NORTH KARELIA PROJECT}

What factors have been most important in the design, operation, and interpretation of the Project? The answer to that question takes on salience as the North Karelia Project may influence programs in other resource poor countries. The development and administration of the Project led its team to consider the following:

Appropriate theory-base: The North Karelia Project epidemiologically adopted a community-based approach — shifting the risk factor distribution of the whole population-targeting changes in lifestyle and culture, especially diet and smoking patterns. The behavioral and social science theories developed for the Project dealt with issues of behavior change, communication-behavior change, innovation diffusion, and community organization..$^{62}$ These strategies were transferred to the national program, including broad policy involvement. ${ }^{63}$

Flexible intervention: Although the North Karelia Project had a strong theoretical orientation, the actual intervention was flexible. Representatives of the Project were very visible and interacted closely with different organizations, responding to the particular social situations of each community.

Intensive intervention: Results of the Project did not depend on correct theoretical frameworks alone, but on much practical work. It was not enough to "do the right thing;" one has also "to do enough of it." A commonly used phrase within the Project was to work with "boots deep in the mud." 
Working with the population: From the very beginning, it was important to work closely with the community. The community "ownership" of the Project was considered crucial, as it was launched after petition by representatives of the people.

Community organization: "Community-based prevention" was the new, innovative approach to CVD in the early 1970s when many questioned whether CVD prevention was possible. From the start, the idea was to change North Karelia as a social and physical environment, because individual behaviors tend to follow the general lifestyle patterns in the community.

Two principles were important. First, much of the Project's success was based on personal contacts. Second, the aim was to find win-win situations, benefitting both the Project and the community.

Official authority: Much of the Project's work was based on voluntary collaboration, persuasion, training, and communication. At the same time, the Project was linked with official administrative structures and health authorities and, as much as possible, with national official guidelines and programs. This emphasized the point that the Project's involvement in health services was not just some voluntary work, but an important part of official duties. In this way, the Project used a tactic of wearing "two hats": an official and unofficial one.

In addition, the coordination of the Project was from within the National Public Health Institute, directly under the Ministry of Health, important for the continuation of the Project and for the transfer of its activities to the national level.

Work with health services: The intervention in North Karelia was broad and all possible areas of life were considered. But it was clearly realized that health services must form the backbone of the intervention. Within local health centers, public health nurses and physicians were considered key. Thus the Project established special and close contacts with them through training seminars, written materials and personal contacts.

Limited targets-outcome orientation: The careful analysis of critical targets was found to be important, as was limiting the number chosen. "Less is more" is a phrase, often referred to. Also in the practical intervention these limited set targets were defined in terms of very practical behaviors, like switching from butter to soft margarines, choosing non fat (or low fat) milk, preferring lean meat, and increasing the consumption of vegetables. In addition, reduction of salt intake (also with replacement by low sodium salts) was stressed, as was smoking cessation.

Bottom-up and top-down: Health promotion discussion often asks whether to use a bottom-up or a top-down approach. In the North Karelia Project clearly a blended model was used. The project started in a bottom-up 
way, with the petition from the people to do something. This was heavily used and it was continuously emphasized that "Only you can change North Karelia." At the same time, international and national expertise identified from a "top-down" perspective the objectives and the many interventions of the Project.

Although the Project was locally popular, the practical messages were not tempting: to change from butter to margarine in a dairy farming culture, to stop smoking when it was seen as a pleasure and of little harm to hard working men. Thus, the Project clearly had to act as a vigorous "change agent" to persuade and gradually introduce its innovations.

Monitoring and feedback: The evaluation system and principles were defined at the outset. It was very soon realized that monitoring should serve more than evaluation. Monitoring of trends with feedback to people through the media was discovered to be one of the strongest intervention modalities. Rapid health behavior monitoring was started with active feedback to the population about the practical changes. This was later transferred to the national level as the national health behavior monitoring system.

From North Karelia to the national level: The original aim of the North Karelia Project was to carry out a comprehensive preventive intervention in North Karelia for a five-year period (1972-1977). In this way North Karelia was seen as a pilot study for all of Finland. After this period, many positive changes were already observed. Thus, the decision was made, encouraged by national authorities, to start to apply the Project experiences nationally, but at the same time to continue carrying out the project in North Karelia as a national "demonstration" or "model". Both North Karelia and all of Finland would benefit from this. National interest helped sustain the North Karelia Project and the visible example of North Karelia helped the national work.

\section{CONCLUSIONS, IMPACT, AND IMPLICATIONS:}

The long march of CHD epidemiology, beginning with the earliest cohort studies in 1947, has provided one model for the successful elucidation and prevention of chronic disease. The agenda for scientific study and for changes in morbidity and mortality were set both by government scientists at the highest levels and by the initiative and determined involvement of CHD researchers. The agenda were problem oriented: what determined the growing rates of CHD morbidity and mortality, how could one build a scientifically based consensus on the causes of both, and how could the evidence of epidemiology and of bench and clinical science be actualized as changes in the cultural practices of the society, both at the individual and 
population level, in order to prevent or postpone the consequences of CHD? The pace and order of each step was not preordained, but evolved as new issues emerged from work in progress. At times, there was impatience with the rate of that pace, not only from communities of scientists and scientific administrators, but from the populations at risk, expressed in the U.S. through congressional committees and most piquantly in Finland from the leaders of a province characterized as having the world's highest rates of CHD.

Given the evidence that has accumulated internationally about CHD prevention by risk factor differences and their reduction, the main question, by the 1980s was no longer "what should be done?" but "how should it be done?" The traditional answer had been to mobilize physicians to profile their patients, and to provide clinical counsel to them, especially those found to be at highest risk. RCTs, which generally focused on higher risk individuals, were methods to test primary and secondary treatment strategies for that segment of the population. But, as this article has described, an essential alternative avenue emerged in the form of community-based primary prevention, a total population approach.

A central aim of those community programs was to translate the congruent findings of basic medical research to large-scale public health programs. The programs were theory-based attempts in real-life situations to overcome the many obstacles to healthy changes. A carefully evaluated community program thereby served as a demonstration project with potential application to wider populations or other communities. They proved, however, difficult to implement and to evaluate, in part because, like contemporary RCTs, they were interventions that occurred during a period of dynamic cultural changes that modified the prevalence of CHD risk factors and the level of medical treatment in the populations under study.

Remarkable changes in the public's health knowledge and behaviors, in cardiac care, and in medical preventive care were documented in American society in the 1980s. These were associated with an accelerated decline in coronary death rates at the rate of three to five percent a year both nationally and in California, Minnesota, and Rhode Island, the sites of the U.S. community-based prevention initiatives. Initial and subsequent coronary disease mortality rates in Minnesota and California were relatively low overall. One conclusion is that placing the studies there was an unfortunate choice of area, population and timing, as low attack rates and rapid social changes reduced the power of the projects to achieve and measure intervention effects.

It seems likely, from the North Karelia experience, that health promotion campaigns in a community at much higher risk, where the population lives in long-term traditional patterns and is also unsophisticated in health 
knowledge and behaviors at the outset, are more likely to achieve a major and measurable population effect than were the 1980s programs among a lower risk, more "sophisticated" and rapidly changing U.S. culture. But what industrial country can now meet such innocent conditions? And what designs have effectively discriminated effects of "natural experiments" from planned interventions?

The 1980s generation of studies in the U.S. neither produced such a design nor an efficiently powerful intervention to meet the extant design conditions. Moreover, those studies were not designed, or permitted to be designed, to discriminate among intervention strategies. Subsequently, the lack of net effect of these three programs on the cross-sectional population trends, over and above the large societal changes of the times, plus the complexity and cost of their design for evaluation and their vast interventions, had a chilling effect on U.S. national policy for research in community health promotion. This was augmented by the very modest effect on community smoking levels of the giant NIH Commit Study in the 1990s, with its random treatment assignment of 11 town pairs and its perhaps unfortunate focus on heavy smokers. ${ }^{64}$

Epidemiologists have since promoted as primary goals the comparison of more limited strategies to achieve individual and population behavioral change, with designs to test the links between the intervention, the exposure ("dose"), and the resulting behavior change. They have suggested that such focused trials be short-term, with frequent small surveys for greater statistical power. . $0,52,65-67^{-6}$

Based on the remarkably positive U.S. experience in discouraging tobacco use over the last 30 years, the "old saw" is still valid: that population strategies (including regulatory components) win out over personal or mediated interventions, at least for diseases or conditions of wide susceptibility and strongly social origins.

If, as indicated above, communities of higher risk, like North Karelia in the 1960s, are the best candidates for successful community-based CHD programs, then changes in global health prevalence mark new areas for such preventions. When community trials of CHD prevention were started, CVDs were seen as "diseases of affluence," as they mainly concerned industrialized countries. However, over the past several decades, noncommunicable diseases (NCDs) have moved to poorer and poorer nations, and within populations these diseases and their risk factors are increasingly accumulating in lower socioeconomic segments. Thus CVD and other chronic NCDs now greatly contribute to health inequality.

The WHO has realized this new global health challenge, and it adopted, in 2000, a Global Strategy on NCD Prevention and Control. It acknowledges 
that NCD prevention and control is now a priority of the organization, and that integrated primary prevention, targeting at the population level the main lifestyle-related risk factors, has the greatest potential for success.

WHO in 2008 intensified its work in the form of a special implementation plan for its global strategy. This is supported by recent risk factor-specific global instruments, including the WHO Framework Convention on Tobacco Control (2003) and the WHO Global Strategy on Diet, Physical Activity and Health (2004). Beyond WHO, the social, economic and population health consequences of CVD and other NCDs led to a Head of State-level Special United Nations Summit on NCDs in New York in September 2011.

The WHO strategies are deeply influenced by those followed by the North Karelia Project and similar community-based primary prevention studies. As the international community draws on the lessons of the North Karelia Project and those of U.S. and international community trials, it is tugging on a thread that connects it to previous agenda, the international series of RCTs that were once the fresh policies of the NIH and its analogues in other countries, and the long train of cohort studies that began in 1947 and produced the paradigm of classic risk factors focused on today. From Framingham to North Karelia, significant groups of epidemiologists and organizations, despite conflict, negotiated scientific agenda with profound influence on population behaviors and public health strategies. It remains to be seen if the international community, prodded by its member states, can successfully produce the agenda required as chronic diseases become the most important disorders in low and middle income countries.

Acronyms list:

$\mathrm{CDP}=$ The Coronary Drug Project

$\mathrm{CHD}=$ Coronary heart disease

$\mathrm{CVD}=$ Cardiovascular disease

MHHP $=$ The Minnesota Heart Health Program

MRFIT $=$ The Multiple Risk Factor Intervention Trial

NCDs $=$ Non-communicable diseases

$\mathrm{NHI}=$ National Heart Institute

NHLBI $=$ National Heart, Lung, and Blood Institute

$\mathrm{NIH}=$ National Institutes of Health

PHS $=$ U.S. Public Health Service

RCTs $=$ Randomized control trials

Acknowledgements: This work was supported in part by a National Endowment for the Humanities Fellowship Award (FA-53395) and a Professional Staff Congress-City University of New York Award (610940039).

Conflicts of Interest: None declared. 


\section{REFERENCES}

1. Strickland SP. Politics, Science, and Dread Disease. Cambridge, MA: Harvard University Press; 1972.

2. Dublin LI. Health Progress, 1936 to 1945. New York, NY: Metropolitan Life Insurance Co. N.D.

3. Fox DM. Power and Illness: The Failure and Future of American Health Policy. Berkeley, CA: University of California Press; 1993.

4. Etheridge EW. Sentinel for Health: A History of the Centers for Disease Control. Berkeley, CA: University of California Press; 1992.

5. Mountin JW. Changing concepts of basic local public health services. In: Selected Papers of Joseph W. Mountin, M.D. Joseph W. Mountin Memorial Committee; 1956.

6. Dawber TR. The Framingham Study: The Epidemiology of Atherosclerotic Disease. Cambridge, MA: Harvard University Press; 1980.

7. Oppenheimer GM. Becoming the Framingham Study 1947-1950. Am J Public Health. 2005;95:602-10.

8. Marks HM. The Progress of Experiment: Science and Therapeutic Reform in the United States, 1900-1990. Cambridge: Cambridge University Press; 1997.

9. Keys A. Nutrition in relation to the etiology and the course of degenerative diseases. J Am Diet Assoc. 1948;24:281-5.

10. Katz LN, Stamler J, Pick R. Nutrition and Atherosclerosis. Philadelphia, PA: Lea \& Febiger; 1958.

11. Aronowitz RA. The social construction of coronary heart disease risk factors. In: Aronowitz RA, editor. Making Sense of Illness: Science, Society and Disease. New York, NY: Cambridge University Press; 1998. p.111-44.

12. White PD. Heart Disease. 3rd edition. New York, NY: The Macmillan Co; 1944.

13. Moriyama IM, Woolsey TD, Stamler J. Observations on possible factors responsible for the sex and race trends in cardiovascular-renal mortality in the United States. J Chronic Dis. 1958;7:401-12.

14. National Heart Institute. Circular number 7. October 1951. Cited in Katz LN, Stamler J. Experimental Atherosclerosis. Springfield, IL: Charles C. Thomas; 1953.

15. Meadors G. Minutes. In: Records of the National Institutes of Health, National Advisory Heart Council, Box 21, National Archives, College Park, Md. June 7, 1948.

16. Clausen JA. Research on the American soldier as a career contingency. Soc Psychol Q. 1984;47:207-13.

17. Moore F. Correspondence to Van Slyke CJ. August 26, 1949. In: Papers of the National Heart, Lung, and Blood Institute, Framingham Heart Disease Epidemiology Study (General) Folder. 
18. Meadors G. Correspondence to Boone B, July 19, 1947. In: Papers of the National Heart, Lung, and Blood Institute, Epidemiology Correspondence Folder.

19. Dawber TR, Moore FE, Mann GV. Coronary heart disease in the Framingham Study. Am J Public Health. 1957;47:4-24.

20. Doyle JT, Dawber TR, Kannel WB, Heslin AS, Kahn H. Cigarette smoking and coronary heart disease: combined experience of the Framingham and Albany studies. N Engl J Med. 1962;266:796-801.

21. Cornfield J. Joint dependence of risk of coronary heart disease in serum cholesterol and systolic blood pressure: a discriminant function analysis. Fed Proc. 1962;21:58-61.

22. Rothstein W. Public Health and the Risk Factor: A History of an Uneven Medical Revolution. Rochester, NY: University of Rochester Press; 2003.

23. Aronowitz R. The social construction of coronary heart disease risk factors. In: Aronowitz R. Making Sense of Illness: Science, Society and Disease. New York, NY: Cambridge University Press; 1998. p.111-44.

24. Dawber TR, Kannel WB. Application of epidemiology of coronary heart disease to medical practice. Modern Medicine. 1962;30:85-101.

25. Max H, DeMets DL, Ware JH. Early Methodological Developments for Clinical Trials at the National Heart, Lung and Blood Institute. Stat Med. 1990;9:88192.

26. Turpeinen O, Miettinen M, Karvonen MJ, Roine P, Pekkarinen M. Lehtosuo EJ, Alivirta P. Dietary prevention of coronary heart disease: long-term experiment. I. Observations on male subjects. Am J Clin Nutr. 1968;21:255-76.

27. Dayton S, Pearce ML, Hashimoto S, Fakler LJ, Hiscock E, Dixon WJ. A controlled clinical trial of a diet high in unsaturated fat. N Engl J Med. 1962;266:1017-23.

28. National Diet-Study Recruitment Group. The National Diet-Heart Study final report. Circulation. 1968;37:S119-24.

29. National Heart Institute. Diet-Heart Review Panel. Mass Field Trials of the Diet Heart Question. New York, NY: American Heart Association; 1969.

30. National Heart Institute. Diet-Heart Review Panel, National Heart and Lung Institute Task Force. Arteriosclerosis, A Report by the National Heart and Lung Institute Task Force on Arteriosclerosis. Washington, DC: U.S. Printing Office; 1971.

31. Coronary Drug Project Research Group. Clofibrate and niacin in coronary heart disease. JAMA. 1975;231:360-81.

32. National Advisory Health Council. Transcripts of Proceedings, 62. 1975.

33. Freis E.D. Reminiscences of the Veterans Administration trial of the treatment of hypertension. Hypertension. 1990;16:472-5.

34. World Health Organization European Collaborative Group. European collaborative trial of multifactorial prevention of coronary heart disease: final report on the 6-year results. Lancet. 1986;1(8486):869-72.

35. Hjermann I, Holme I, Leren P. Oslo Study Diet and AntiSmoking Trial. Results after 102 months. Am J Med. 1986;80:7-11. 
36. Cooper T. Arteriosclerosis: policy, polity, and parity. Circulation. 1972;45:43340.

37. Multiple Risk Factor Intervention Trial Research Group. Multiple Risk Factor Intervention Trial. Risk factor changes and mortality results. JAMA. 1982;248:1465-77.

38. Hypertension Detection and Follow-up Program Cooperative Group. The effect of treatment on mortality in "mild" hypertension. Results of the Hypertension Detection and Follow-up Program. N Engl J Med. 1982;307:976-80.

39. Lipid Research Clinics. The Lipid Research Clinics Coronary Primary Prevention Trial results 1 . Reduction in incidence of coronary heart disease. JAMA. 1984;251:351-64.

40. The Pooling Project Research Group. Relationship of blood pressure, serum cholesterol, smoking habits, relative weight and ECG abnormalities to the incidence of major coronary events: final report of the Pooling Project. J Chronic Dis. 1978;31:201-306.

41. Farquhar JW, Maccoby N, Wood PD, et al. (1977). Community education for cardiovascular health. Lancet, 1977;1:1192-5.

42. Keys A, et al. Coronary heart disease in seven countries. Circulation. 1970; 41:S1-211.

43. Blackburn H. Research and demonstrations projects in community cardiovascular disease prevention. J Public Health Policy. 1983;4:398-421.

44. Report of the Makarska Conference on Mass Field Trials for the Prevention of Coronary Heart Disease. International Society of Cardiology. Makarska, Yugoslavia. CVD History Archive: School of Public Health, Univ. of Minnesota; 1968. Available from URL: http://www.epi.umn.edu/cvdepi/ photo_doc.asp?id=981 (Accessed 22 December, 2011).

45. Puska P, et al. The North Karelia project. 20-year results and experiences. Helsinki: National Public Health Institute; 1995.

46. Mass Field Trials on the Prevention of Coronary Heart Disease: Perspectives and Tasks. Report of an International Working Meeting Makarska, Yugoslavia, 19-24 September, 1968. Available from URL: http://www.epi.umn.edu/cvdepi/ pdfs/Makarska\%20doc.pdf (Accessed 22 December, 2011).

47. Farquhar JW, Fortmann SP, Maccoby N, Haskell WL, Williams PT, Flora, JA, et al. The Stanford Five-City Project: Design and methods. Am J Epidemiol. 1985;122:323-34.

48. Jacobs DR Jr, Luepker RV, Mittelmark MB, Folsom AR, Pirie PL, Mascili SR, et al. Communitywide prevention strategies: Evaluation design of the Minnesota Heart Health Program. J Chronic Dis. 1986;39:775-88.

49. Carleton RA, Lasater TM, Assaf A, Lefebvre RC, McKinlay SM. The Pawtucket Heart Health Program: an experiment in population-based disease prevention. R I Med J. 1987;70:533-8.

50. Murray DM. Design and analysis of community trials: Lessons from the Minnesota Heart Health Program. Am J Epidemiol. 1995;142:569-75. 
51. Blackburn H. Community programmes in coronary heart disease prevention and health promotion: Changing community behavior. In: Coronary Heart Disease Epidemiology. Marmot M, Elliott P, editors. New York, NY: Oxford University Press; 1992.

52. Winkleby MA, Feldman HA, Murray DM. Joint analysis of three U.S. community intervention trials for reduction of cardiovascular disease risk. J Clin Epidemiol. 1997;50:6545-658.

53. Kannisto V. Kuolemansyyt väestöllisinä tekijöinä Suomessa. [Finnish]: Causes of death as demographic factors in Finland. Helsinki: Kansantaloudellinen yhdistys; 1947.

54. Keys A. The cholesterol problem. Voeding. 1952;13:539-55.

55. Keys A, Karvonen MJ, Fidanza F. Serum-cholesterol studies in Finland. Lancet. 1958;2:175-8.

56. Roine P., Pekkarinen M., Karvonen M.J., Kihlberg J.(1958). Diet and cardiovascular disease in Finland. Lancet. 1958;2;173-5.

57. Editorial. Shot-gun prevention? Int J Epidemiol. 1973;2:219-20.

58. Puska P, Tuomilehto, Nissinen A, Vartiainen E. The North Karelia Project 20 year results and experiences. Helsinki: National Public Health Institute; 1995.

59. Puska P, Vartiainen E, Laatikainen T, Jousilahti P, Paavola M, editors. The North Karelia Project: From North Karelia to National Action. Helsinki: The National Institute for Health and Welfare (THL); 2009.

60. Vartiainen E, Laatikainen T, Peltonen M, Juolevi A, Männistö S, Sundvall J, et al. Thirty-five-year trends in cardiovascular risk factors in Finland. Int $\mathrm{J}$ Epidemiol. 2010;39:504-18.

61. Laatikainen T, Critchley J, Vartiainen E, Salomaa V, Ketonen M, Capewell S. Explaining the decline in coronary heart disease mortality in Finland between 1982 and 1997. Am J Epidemiol. 2005;162:764-73.

62. Puska P, Nissinen A, Tuomilehto J, Salonen JT, Koskela K, McAlister A, et al. The community-based strategy to prevent coronary heart diseases: conclusions from the ten years of the North Karelia Project. Ann Rev Public Health. 1985;6:47-193.

63. Puska P, Ståhl T. Health in All Policies - The Finnish Initiative: background, principles, and current issues. Ann Rev Public Health. 2010;31:27.1-27.14.

64. Community Intervention Trial for Smoking Cessation (COMMIT): I. cohort results from a four-year community intervention. Am J Public Health. 1995;85:183-92.

65. Luepker RV. Community trials. Preventive Med. 1994;23:602-5.

66. Luepker RV, Murray DM, Jacobs DR, Mittlemark MB Bracht N, Carlaw R, et al. Community education for cardiovascular disease prevention: risk factor changes in the Minnesota Heart Health Program. Am J Public Health. 1994;94:1383-93.

67. Susser M. The tribulations of trials-interventions in communities. (Editorial) Am J Public Health, 1995;85:156-8. 